\title{
Composição Mineral das Pastagens das Regiões Norte e Noroeste do Estado do Rio de Janeiro. 2. Manganês, Ferro, Zinco, Cobre, Cobalto, Molibdênio e Chumbo ${ }^{1}$
}

\author{
Fernando Luiz Henriques Tebaldi ${ }^{2}$, José Fernando Coelho da Silva ${ }^{3}$, Hernan Maldonado \\ Vasquez ${ }^{4}$, José Tarcísio Lima Thiebaut ${ }^{5}$
}

\begin{abstract}
RESUMO - Os teores de $\mathrm{Mn}, \mathrm{Fe}, \mathrm{Zn}, \mathrm{Cu}, \mathrm{Co}$, Mo e $\mathrm{Pb}$ dos solos, das forrageiras predominantes nas pastagens e da água foram estudados nas regiões Norte e Noroeste do Estado do Rio de Janeiro, nas épocas seca (junho-julho) e chuvosa (dezembro-janeiro) do ano. Amostras de solo, forrageiras e água foram coletadas em 12 diferentes locais das regiões, em áreas onde predominam pastagens, identificadas por fotos obtidas por satélite e de acordo com as diferentes características dos solos. Os teores de minerais das amostras foram determinados por espectrometria via plasma, após preparados os extratos. Em ambas épocas, foram encontrados baixos níveis de $\mathrm{Cu}$ e Zn nas amostras de forrageiras e o teor de minerais variou com o tipo de solo. Os teores de Fe e Mn das forrageiras foram superiores às exigências dos bovinos, e deficiências de $\mathrm{Cu}$ e $\mathrm{Zn}$ foram encontradas. Os teores de Co nas forrageiras foram superiores às exigências dos bovinos. Os microelementos analisados na água foram, em geral, muito baixos, quando comparados com os níveis de segurança. Os teores de minerais das amostras de água analisadas estão dentro dos níveis de segurança para os animais domésticos.
\end{abstract}

Palavras chave: água, forrageira, microelemento, pastagem, solo

\section{Mineral Composition of Pastures in the North and Northwest Regions of Rio de Janeiro State. 2. Manganese, Iron, Zinc, Copper, Cobalt, Molybdenum and Lead}

\begin{abstract}
The contents of $\mathrm{Mn}, \mathrm{Fe}, \mathrm{Zn}, \mathrm{Cu}, \mathrm{Co}$, Mo and $\mathrm{Pb}$ of soil, predominant forage in the pastures and water, were studied in the North and Northwest regions of Rio de Janeiro State, during the dry (June-July) and rainy (December-January) seasons. Samples of soil, forage and water were collected in 12 different points of the regions, in predominant grazing areas, as determined by satellite photograph and according to different soil characteristics. The mineral contents of the sample extracts were determined by spectrometry, on a inductive plasma emission source apparatus. In both seasons it was found low levels of $\mathrm{Cu}$ and $\mathrm{Zn}$ in forage samples and the mineral contents of forages varied with the type of soil. The levels of $\mathrm{Fe}$ and $\mathrm{Mn}$ were higher than the requirements and deficiencies of $\mathrm{Cu}$ and $\mathrm{Zn}$ were found. The cobalt contents of forages were higher than cattle requirements. The analyzed microelements in water usually were very low when compared with the safety levels. It was concluded that the mineral contents in the water analyzed samples were within the safety margin for domestic animals.
\end{abstract}

Key Words: forage, microelement, pasture, soil, water

\section{Introdução}

Existem cerca de 17 elementos inorgânicos requeridos pelos bovinos, dentre eles os macroelementos incluem cálcio, fósforo, magnésio, potássio, sódio, cloro e enxofre e os microelementos, cromo, cobalto, cobre, iodo, ferro, manganês, molibdênio, níquel, selênio e zinco. Outros elementos, como o arsênico, boro, chumbo, silício e vanádio, parecem ser essenciais para outras espécies animais, mas não há evidência, até o presente, de que eles sejam importantes para bovinos (NATIONAL RESEARCH COUNCIL - NRC, 1996).
Deficiência de Mn foi diagnosticada, com base em análises do mineral no fígado, na região Norte do Mato Grosso por Mendes em 1977 e Sousa et al. em 1981, citados por TOKARNIA et al. (1988), que concluíram serem estas deficiências de Mn no fígado devidas às altas concentrações de Fe nas forragens e à elevada suplementação mineral com Co, o que provoca problemas na absorção e utilização do mesmo.

Conforme GUIMARÃES et al. (1980), até 19 ppm de Mn nas gramíneas, considera-se deficiente em Mn, de 20-120 ppm, nível adequado do mineral nas gramíneas e acima de 120 ppm, nível alto de Mn.

\footnotetext{
${ }^{1}$ Parte da Dissertação de Mestrado apresentada pelo primeiro autor, à Universidade Estadual do Norte Fluminense, Campos dos Goytacazes, RJ.

2 Zootecnista, UFV, MS em Produção Animal, CCTA, UENF.

3 Docente LZNA, CCTA, UENF, Bolsista do CNPq. E.mail: jcoelho@uenf.br

${ }^{4}$ Docente LZNA, CCTA, UENF, 28015-620 Campos dos Goytacazes, RJ. E.mail: hernan@uenf.br

5 Laboratório de Estatística Experimental e Análise Econômica, CCTA, UENF, 28015-620, Campos dos Goytacazes, RJ.
} 
A deficiência de Fe geralmente não é esperada em bovinos que vivem em condições de pasto, pois as forragens fornecem teores superiores às exigências dos mesmos (MARQUES et al., 1981), à exceção para pastagens localizadas em terrenos arenosos, brancos ou acinzentados (SILVA, 1981; MILLER, 1981; e MILLER e RAMSEY,1988).

Em revisão feita por TOKARNIA et al. (1988), verificou-se que, no levantamento das deficiências minerais em bovinos no Norte do Mato Grosso, o nível de Fe no fígado e em forrageiras, em todas as seis fazendas estudadas foi considerado adequado; no solo foi ligeiramente baixo em duas fazendas, variando de médio a adequado nas outras quatro. No Nordeste de Roraima, os níveis hepáticos nas forrageiras eram adequados e no solo estavam acima das concentrações recomendadas para as culturas.

SOUSA e DARSIE (1985), fazendo levantamento das deficiências minerais em bovinos no Nordeste de Roraima, concluíram que existe deficiência de $\mathrm{Zn}$ nas forrageiras em toda região estudada, e os níveis de $\mathrm{Zn}$ no fígado dos animais também foram baixos, sendo estas deficiências mais pronunciadas no período chuvoso, (79 ppm em animais adultos e 76 ppm em animais jovens).

Segundo GUIMARÃES et al. (1980), para bovinos, o teor de Cu em gramíneas de até 4 ppm deve ser considerado deficiente, de 5 a 15 ppm, adequado e acima de 16 ppm, nível alto.

As necessidades de $\mathrm{Cu}$ não podem ser definidas claramente nos ruminantes, quando estão presentes na dieta diversos fatores que provocam interferências. A forragem que contém 3-6 ppm de Cu está na faixa ideal (CHURCH, 1988). Entretanto, acima de $10 \mathrm{ppm}$ de $\mathrm{Cu}$, pode ser requerido para bovinos em pastejo ou consumindo alimentos que contenham altos níveis de Mo (TEIXEIRA, 1991). Proporção de $\mathrm{Cu}$ :Mo não inferior a 4:1 assegura disponibilidade adequada de $\mathrm{Cu}$ (CHURCH, 1988).

O Cu disponível nos alimentos é altamente dependente do conteúdo de $\mathrm{Cu}$ no solo, além disso, a absorção de $\mathrm{Cu}$ e utilização são afetadas por muitos outros nutrientes, como o $\mathrm{Mo}, \mathrm{Ca}, \mathrm{Hg}, \mathrm{Cd}, \mathrm{Zn}$ e Fe (ENSMINGER et al., 1990).

Em ruminante, ocorre deficiência de $\mathrm{Cu}$ principalmente sob condições de pastejo, sendo raros os sinais de deficiência, quando a dieta é suplementada com alimentos concentrados. Deficiência de $\mathrm{Cu}$ geralmente ocorre quando o Mo da forragem excede a $3 \mathrm{ppm}$ e o nível de Cu é inferior a 5 ppm (Ward, em 1977, citado por CONRAD et al., 1985; MARTIN, 1993).

Em revisão feita por TOKARNIA e DÖBEREINER, (1973), foi identificada deficiência de Co no Norte do Espírito Santo; no Vale do Rio São Francisco, no Oeste da Bahia; nos Vales dos Rios Uruçuí e Gurguéia, no Sudeste do Piauí; e na Chapada do Maranhão. Houve também indicação de deficiência na Região de Bragança no Pará e em várias áreas do Centro-sul de Mato Grosso. TOKARNIA et al. (1988), em outra revisão, confirmaram que deficiências de $\mathrm{Cu}$ e $\mathrm{Co}$, depois da deficiência de $\mathrm{P}$, foram as mais comuns no Brasil.

Segundo GUIMARÃES et al. (1980), o nível de Mo em gramíneas de até 0,5 ppm é deficiente; de 0,6 a 1,5 ppm, adequado; e acima de 1,6 ppm, alto.

Estima-se o requerimento de Mo para animais em pastejo em 0,01 ppm ou menos, e nenhuma deficiência de Mo foi publicada ou identificada em animais em pastejo (CONRAD et al., 1985).

Allcroft (1951) relatou que a ingestão de aproximadamente 200 a $400 \mathrm{mg}$ de $\mathrm{Pb} / \mathrm{kg}$ de peso vivo em um dia, na forma de acetato, carbonato ou óxido, é suficiente para causar a morte em bezerros com até 4 meses de idade. Bovinos adultos podem requerer dose oral de 600 a $800 \mathrm{mg} / \mathrm{kg}$ de peso vivo para produzir o mesmo efeito (Buck, 1970). A repetição de pequenas doses tem efeito acumulativo, produzindo também toxidez. O consumo diário de aproximadamente 6 a $7 \mathrm{mg} / \mathrm{kg}$ de peso vivo parece ser a dose mínima capaz de causar toxidez em bovinos (Hammond e Aronson 1964, todos citados por Mc DOWELL et al., 1976).

Elementos como Al, Fe, Bo, Co, Cu, Cr, I, Mo, Mn e $\mathrm{Zn}$ comumente ocorrem na água, mas raramente oferecem algum problema para os animais domésticos. Nenhum deles tende a se acumular no leite, ovos ou carne (SHIRLEY e CARVALHO, 1976).

No presente estudo, foram analisados os teores de $\mathrm{Mn}, \mathrm{Fe}, \mathrm{Zn}, \mathrm{Cu}, \mathrm{Co}$, Mo e $\mathrm{Pb}$ nos solos, nas forrageiras e na água das regiões Norte e Noroeste do Estado do Rio de Janeiro.

\section{Material e Métodos}

A identificação dos locais, da coleta e do preparo das amostras foram descritas por TEBALDI et al. (2000). Nas amostras de solo, forrageiras e água, foram determinados os teores de $\mathrm{Mn}, \mathrm{Fe}, \mathrm{Zn}, \mathrm{Cu}, \mathrm{Mo}$ e $\mathrm{Pb}$, os demais procedimentos e interpretações dos resultados também foram descritos por TEBALDI et al. (2000). 


\section{Resultados e Discussão}

\section{Manganês}

Os teores de Mn nos solos (Tabela 1) variaram em função dos locais e das profundidades $(\mathrm{P}<0,01)$, sem diferença entre épocas $(\mathrm{P}>0,05)$, ocorrendo também interação de local e profundidade e de profundidade e época $(\mathrm{P}<0,01)$. Somente em CamposCaxeta, na profundidade de $20 \mathrm{~cm}$, e em S.J.Barra, em ambas profundidades (20 a $40 \mathrm{~cm}$ ), não houve diferença entre épocas.

O nível de Mn mais alto foi encontrado nos solos de Italva (127,00 ppm) e o mais baixo, em S.J.Barra (2,40 ppm).

Pode-se concluir que os níveis de Mn nos solos estudados são satisfatórios, visto que as forrageiras analisadas nos locais pesquisados não estavam abaixo do índice sugerido por GUIMARÃES et al. (1980).

Houve efeito $(\mathrm{P}<0,01)$ de local, época e interação desses fatores sobre os teores de Mn das forrageiras.
Conforme Tabela 2, em cinco dos locais estudados, os teores de $\mathrm{Mn}$ decresceram $(\mathrm{P}<0,05)$ da época seca para a época chuvosa (comportamento decrescente). Nas regiões de S.M.Madalena e Italva, os teores de $\mathrm{Mn}$ nas forrageiras foram menores na época seca $(\mathrm{P}<0,05)$ e nos outros quatro locais não foram observadas diferenças significativas entre épocas, sendo esses locais enquadrados no comportamento de pequena variação.

Comparando-se os níveis de Mn encontrados nas forragens analisadas neste trabalho com os níveis sugeridos por GUIMARÃES et al. (1980), nota-se que, nas épocas e nos locais estudados, não houve deficiências de Mn nas forrageiras, já que todas as médias locais e de épocas foram superiores a 19 ppm deste mineral nas forragens.

Os resultados na Tabela 2 confirmam as pesquisas de Andreasi et al., citados por CARDOSO (1983), e de MARTIN (1993), em que os níveis de Mn nas forrageiras estão acima das exigências dos bovinos, bem como dos requerimentos dietéticos mínimos para

Tabela 1 - Teores médios de Mn (ppm) nos solos, nas épocas seca (Ep1) e chuvosa (Ep2), nas profundidades de 20 (1) e $40 \mathrm{~cm}$ (2), nos diferentes locais, e seus respectivos números de identificação $(\mathrm{N})$

Table 1 - Average Mn contents (ppm) in the soils, in the dry (Ep1) and rainy (Ep2) seasons, in the depths of 20 (1) and $40 \mathrm{~cm}$ (2) in the different places and the respective identification numbers $(N)$

\begin{tabular}{|c|c|c|c|c|c|}
\hline $\begin{array}{l}\text { Local } \\
\text { Place }\end{array}$ & $\mathrm{N}$ & $\begin{array}{l}\text { Profundidade } \\
\text { Depth }\end{array}$ & Ep1 & Ep2 & $\begin{array}{c}\text { Médias } \\
\text { Means }\end{array}$ \\
\hline \multirow[t]{2}{*}{ Italva } & \multirow[t]{2}{*}{11} & 1 & $144,00^{\mathrm{b}}$ & $127,67^{\mathrm{a}}$ & 135,83 \\
\hline & & 2 & $137,00^{b}$ & $98,33^{\mathrm{a}}$ & 117,67 \\
\hline \multirow[t]{2}{*}{ B.J.Itabapoana } & \multirow[t]{2}{*}{6} & 1 & $123,33^{b}$ & $47,67^{\mathrm{a}}$ & 85,50 \\
\hline & & 2 & $70,00^{\mathrm{b}}$ & $57,33^{\mathrm{a}}$ & 63,67 \\
\hline \multirow[t]{2}{*}{ S.M.Madalena } & \multirow[t]{2}{*}{3} & 1 & $6,00^{\mathrm{b}}$ & $3,00^{\mathrm{a}}$ & 4,50 \\
\hline & & 2 & $5,67^{b}$ & $2,33^{\mathrm{a}}$ & 4,00 \\
\hline \multirow[t]{2}{*}{ Miracema } & \multirow[t]{2}{*}{7} & 1 & $6,33^{\mathrm{b}}$ & $3,67^{\mathrm{a}}$ & 5,00 \\
\hline & & 2 & $4,00^{\mathrm{b}}$ & $2,00^{\mathrm{a}}$ & 3,00 \\
\hline \multirow[t]{2}{*}{ Campos-Itereré } & \multirow[t]{2}{*}{12} & 1 & $74,00^{\mathrm{a}}$ & $204,67^{b}$ & 139,33 \\
\hline & & 2 & $32,00^{\mathrm{a}}$ & $106,00^{\mathrm{b}}$ & 69,00 \\
\hline \multirow[t]{2}{*}{ Itaperuna } & \multirow[t]{2}{*}{10} & 1 & $26,33^{\mathrm{a}}$ & $33,33^{b}$ & 29,83 \\
\hline & & 2 & $35,33^{\mathrm{a}}$ & $45,00^{\mathrm{b}}$ & 40,17 \\
\hline \multirow[t]{2}{*}{ Campos-Caxeta } & \multirow[t]{2}{*}{9} & 1 & $2,67^{\mathrm{a}}$ & $3,67^{\mathrm{a}}$ & 3,17 \\
\hline & & 2 & $1,67^{\mathrm{a}}$ & $4,33^{b}$ & 3,00 \\
\hline \multirow[t]{2}{*}{ S.F.Itabapoana } & \multirow[t]{2}{*}{1} & 1 & $28,67^{\mathrm{a}}$ & $30,33^{\mathrm{a}}$ & 29,50 \\
\hline & & 2 & $25,00^{\mathrm{a}}$ & $24,33^{\mathrm{a}}$ & 24,67 \\
\hline \multirow[t]{2}{*}{ Campos-Carvão } & \multirow[t]{2}{*}{5} & 1 & $28,67^{b}$ & $22,67^{\mathrm{a}}$ & 25,67 \\
\hline & & 2 & $0,00^{\mathrm{a}}$ & $16,00^{\mathrm{b}}$ & 8,00 \\
\hline \multirow[t]{2}{*}{ S.A.Pádua } & \multirow[t]{2}{*}{8} & 1 & $123,33^{b}$ & $98,00^{\mathrm{a}}$ & 110,67 \\
\hline & & 2 & $84,33^{\mathrm{a}}$ & $88,33^{\mathrm{b}}$ & 86,33 \\
\hline \multirow[t]{2}{*}{ Campos-S.Maria } & \multirow[t]{2}{*}{2} & 1 & $87,00^{\mathrm{b}}$ & $72,33^{\mathrm{a}}$ & 79,67 \\
\hline & & 2 & $58,33^{\mathrm{a}}$ & $68,67^{b}$ & 63,50 \\
\hline \multirow[t]{2}{*}{ S.J.Barra } & \multirow[t]{2}{*}{4} & 1 & $1,00^{\mathrm{a}}$ & $7,67^{\mathrm{a}}$ & 4,33 \\
\hline & & 2 & $0,00^{\mathrm{a}}$ & $1,00^{\mathrm{a}}$ & 0,50 \\
\hline
\end{tabular}

Dentro de cada local e para cada profundidade, médias seguidas de mesma letra não diferem, pelo teste de $F$, a $5 \%$ de probabilidade.

Within each place and for each depth, means followed by the same letter do not differ, by F test, at $5 \%$ level of probability. 
TEBALDI et al.

Tabela 2 - Teores médios de Mn (mg/kg na MS) das forrageiras nas épocas seca (Ep1) e chuvosa (Ep2) nos diferentes locais e seus respectivos números de identificação $(\mathrm{N})$

Table 2 - Average Mn contents ( $\mathrm{mg} / \mathrm{kg}$ of dry matter) of the forages, in the dry (Ep1) and rainy (Ep2) seasons, in the different places and the respective identification numbers $(N)$

\begin{tabular}{lclccc}
\hline $\begin{array}{l}\text { Comportamento } \\
\text { Behavior }\end{array}$ & $\mathrm{N}$ & $\begin{array}{l}\text { Locais } \\
\text { Places }\end{array}$ & Ep1 & Ep2 & $\begin{array}{c}\text { Médias } \\
\text { Means }\end{array}$ \\
\hline Decrescente & 12 & Campos-Itereré & $362,05^{\mathrm{b}}$ & $190,21^{\mathrm{a}}$ & 276,10 \\
Decreasing & 9 & Campos-Caxeta & $348,27^{\mathrm{b}}$ & $187,03^{\mathrm{a}}$ & 267,40 \\
& 7 & Miracema & $348,34^{\mathrm{b}}$ & $125,80^{\mathrm{a}}$ & 226,74 \\
& 8 & S.A.Pádua & $299,30^{\mathrm{b}}$ & $141,10^{\mathrm{a}}$ & 220,20 \\
& 1 & S.F. Itabapoana & $221,80^{\mathrm{b}}$ & $60,30^{\mathrm{a}}$ & 140,90 \\
\hline Crescente & 3 & S.M. Madalena & $379,90^{\mathrm{a}}$ & $591,10^{\mathrm{b}}$ & 485,00 \\
Increasing & 11 & Italva & $366,30^{\mathrm{a}}$ & $399,50^{\mathrm{b}}$ & 382,00 \\
\hline Pequena variação & 5 & Campos-Carvão & $225,60^{\mathrm{a}}$ & $221,50^{\mathrm{a}}$ & 223,80 \\
Small variation & 2 & Campos-S.Maria & $251,60^{\mathrm{a}}$ & $189,00^{\mathrm{a}}$ & 220,30 \\
& 6 & B.J.Itabapoana & $208,65^{\mathrm{a}}$ & $227,15^{\mathrm{a}}$ & 219,50 \\
& 10 & Itaperuna & $196,00^{\mathrm{a}}$ & $200,40^{\mathrm{a}}$ & 199,00 \\
& 4 & S.J.Barra & $104,25^{\mathrm{a}}$ & $57,85^{\mathrm{a}}$ & 81,05 \\
\hline
\end{tabular}

Dentro de cada local, médias seguidas de mesma letra não diferem, pelo teste de $F$, a $5 \%$ de probabilidade.

Within each place, means followed by the same letter do not differ, by $F$ test, at $5 \%$ level of probability.

ruminantes citados por CONRAD et al. (1985), e para diversas categorias de bovinos (Ammerman e Goodrich 1983, citados por CHURCH, 1988).

Não foi encontrada correlação significativa entre níveis de Mn nos solos e nas forrageiras ( $\mathrm{r}=0,20, \mathrm{P}=0,27)$.

Em relação ao NATIONAL RESEARCH COUNCIL - NRC (1996), pode-se afirmar também que a exigência de Mn para gado de corte é atendida, visto que a sua recomendação é de 20 ppm para bovinos em crescimento e 40 ppm para vacas. Já que o NRC (1996) determina $1000 \mathrm{mg} / \mathrm{kg}$ como concentração máxima tolerável, o que é cerca de duas vezes o maior teor encontrado, não há possibilidade de ocorrer toxidez.

\section{Ferro}

Os teores de Fe dos solos (Tabela 3) variaram em função das épocas, profundidades e dos locais $(\mathrm{P}<0,01)$ estudados, observando-se nas médias locais, variações de dez a onze vezes entre o menor e o maior teor deste elemento. Houve também interação de local e profundidade e de local e época $(\mathrm{P}<0,01)$. Somente em S.F.Itabapoana, na profundidade de $40 \mathrm{~cm}$, e em S.J.Barra, na profundidade de $20 \mathrm{~cm}$, não foi constatada diferença entre épocas $(\mathrm{P}>0,05)$.

Houve efeito de local, época do ano e interação desses fatores $(\mathrm{P}<0,01)$ sobre as concentrações de $\mathrm{Fe}$ das forrageiras. Os teores de $\mathrm{Fe}$ nas forrageiras (Tabela 4) em nove locais estudados foram menores na época chuvosa (comportamento decrescente) em relação à seca $(\mathrm{P}<0,05)$; já em Campos-Carvão, o comportamento foi inverso $(\mathrm{P}<0,01) \mathrm{e}, \mathrm{em} \mathrm{S}$. A. Pádua e S.M.Madalena, não houve diferença entre épocas, sendo enquadrados como de pequena variação.

Não se encontrou correlação significativa entre os níveis de Fe nos solos e nas forrageiras $(r=0,31$, $\mathrm{P}=0,16$ ).

Os resultados obtidos neste trabalho confirmam os de MARQUES et al. (1981), os quais relataram que, geralmente, não é esperada deficiência de $\mathrm{Fe}$ em bovinos criados em regime de pasto, já que as forrageiras fornecem teores bem superiores às exigências dos animais. Também em levantamentos feitos por TOKARNIA et al. (1988), em várias regiões do Brasil, encontraram-se níveis adequados de $\mathrm{Fe}$ nas forrageiras analisadas.

Quando se comparam os dados obtidos neste trabalho com a exigência de $\mathrm{Fe}$ recomendada pelo NRC (1996), que é de 50 ppm para novilhos de corte em acabamento, novilhas em gestação e vacas em lactação, observa-se que os níveis encontrados são bem acima das exigências dos bovinos. Já com relação ao nível de toxidez, segundo o NRC (1996), este valor é de 1000 ppm, portanto, o maior valor encontrado está bem longe de atingir tal marca.

Zinco

Os teores de $\mathrm{Zn}$ nos solos (Tabela 5) variaram $(\mathrm{P}<0,05)$ em função dos locais, das épocas $(\mathrm{P}<0,01)$ e profundidades $(\mathrm{P}<0,05)$. Os teores foram sempre menores na época seca, com excessão de S.J.Barra na profundidade de $40 \mathrm{~cm}$, onde não se constatou diferença entre épocas. As médias locais variaram de 8,68 ppm, como teor mais alto encontrado em Campos-Itereré, até 2,35 ppm, como o nível mais 
Tabela 3 - Teores médios de Fe (ppm) nos solos, nas épocas seca (Ep1) e chuvosa (Ep2), nas profundidades de 20 (1) e $40 \mathrm{~cm}$ (2), nos diferentes locais e seus respectivos números de identificação $(\mathrm{N})$

Table 3 - Average Fe contents (ppm) in the soils, in the dry (Ep1) and rainy (Ep2) seasons, in the depths of 20 (1) and $40 \mathrm{~cm}$ (2) in the different places and the respective identification numbers $(N)$

\begin{tabular}{|c|c|c|c|c|c|}
\hline $\begin{array}{l}\text { Locais } \\
\text { Places }\end{array}$ & $\mathrm{N}$ & $\begin{array}{c}\text { Profundidade } \\
\text { Depth }\end{array}$ & Ep1 & Ep2 & $\begin{array}{c}\text { Médias } \\
\text { Means }\end{array}$ \\
\hline \multirow{2}{*}{ Campos-Itereré } & \multirow[t]{2}{*}{12} & 1 & $343,67^{a}$ & $535,33^{b}$ & 439,50 \\
\hline & & 2 & $154,33^{a}$ & $538,67^{\mathrm{b}}$ & 346,50 \\
\hline \multirow[t]{2}{*}{ Campos-Carvão } & \multirow[t]{2}{*}{5} & 1 & $292,33^{\mathrm{a}}$ & $382,67^{b}$ & 337,50 \\
\hline & & 2 & $206,67^{a}$ & $215,33^{b}$ & 211,00 \\
\hline \multirow[t]{2}{*}{ S.M.Madalena } & \multirow[t]{2}{*}{3} & 1 & $157,67^{a}$ & $226,67^{b}$ & 192,17 \\
\hline & & 2 & $234,00^{\mathrm{a}}$ & $249,00^{\mathrm{b}}$ & 241,50 \\
\hline \multirow[t]{2}{*}{ Miracema } & \multirow[t]{2}{*}{7} & 1 & $104,33^{\mathrm{a}}$ & $121,67^{b}$ & 113,00 \\
\hline & & 2 & $63,67^{\mathrm{a}}$ & $95,67^{\mathrm{b}}$ & 79,67 \\
\hline \multirow[t]{2}{*}{ B.J.Itabapoana } & \multirow[t]{2}{*}{6} & 1 & $31,67^{\mathrm{a}}$ & $258,67^{b}$ & 145,17 \\
\hline & & 2 & $36,33^{\mathrm{a}}$ & $34,00^{\mathrm{b}}$ & 35,17 \\
\hline \multirow[t]{2}{*}{ S.A.Pádua } & \multirow[t]{2}{*}{8} & 1 & $37,33^{\mathrm{a}}$ & $116,67^{b}$ & 77,00 \\
\hline & & 2 & $35,67^{\mathrm{a}}$ & $115,33^{b}$ & 75,50 \\
\hline \multirow[t]{2}{*}{ Itaperuna } & \multirow[t]{2}{*}{10} & 1 & $48,00^{\mathrm{a}}$ & $52,33^{\mathrm{b}}$ & 50,17 \\
\hline & & 2 & $54,33^{b}$ & $50,00^{\mathrm{a}}$ & 52,17 \\
\hline \multirow[t]{2}{*}{ Italva } & \multirow[t]{2}{*}{11} & 1 & $42,00^{\mathrm{a}}$ & $44,00^{\mathrm{b}}$ & 43,00 \\
\hline & & 2 & $31,33^{b}$ & $25,00^{\mathrm{a}}$ & 28,17 \\
\hline \multirow[t]{2}{*}{ S.F.Itabapoana } & \multirow[t]{2}{*}{1} & 1 & $31,67^{\mathrm{a}}$ & $33,33^{\mathrm{b}}$ & 32,50 \\
\hline & & 2 & $38,67^{\mathrm{a}}$ & $37,67^{\mathrm{a}}$ & 38,17 \\
\hline \multirow[t]{2}{*}{ Campos-Caxeta } & \multirow[t]{2}{*}{9} & 1 & $169,00^{\mathrm{b}}$ & $138,00^{\mathrm{a}}$ & 153,50 \\
\hline & & 2 & $296,33^{b}$ & $160,00^{\mathrm{a}}$ & 228,17 \\
\hline \multirow[t]{2}{*}{ S.J.Barra } & \multirow[t]{2}{*}{4} & 1 & $104,33^{\mathrm{a}}$ & $49,33^{a}$ & 76,83 \\
\hline & & 2 & $51,00^{\mathrm{b}}$ & $22,00^{\mathrm{a}}$ & 36,50 \\
\hline \multirow[t]{2}{*}{ Campos-S.Maria } & \multirow[t]{2}{*}{2} & 1 & $29,33^{b}$ & $25,67^{\mathrm{a}}$ & 27,50 \\
\hline & & 2 & $45,67^{\mathrm{b}}$ & $40,67^{\mathrm{a}}$ & 43,17 \\
\hline
\end{tabular}

Dentro de cada local e para cada profundidade, médias seguidas de mesma letra não diferem, pelo teste de $\mathrm{F}$, a $5 \%$ de probabilidade.

Within each place and for each depth, means followed by the same letter do not differ, by F test, at $5 \%$ level of probability.

Tabela 4 - Teores médios de Fe (mg/kg na MS) das forrageiras, nas épocas seca (Ep1) chuvosa (Ep2), nos diferentes locais, e seus respectivos números de identificação (N)

Table 4 - Average FE contents ( $\mathrm{mg} / \mathrm{kg}$ of dry matter) of the forages, in the dry (Ep1) and rainy (Ep2) seasons, in the different places and the respective identification numbers $(N)$

\begin{tabular}{lclcrc}
\hline $\begin{array}{l}\text { Comportamento } \\
\text { Behavior }\end{array}$ & $\mathrm{N}$ & $\begin{array}{c}\text { Locais } \\
\text { Places }\end{array}$ & Ep1 & Ep2 & $\begin{array}{c}\text { Médias } \\
\text { Means }\end{array}$ \\
\hline $\begin{array}{l}\text { Decrescente } \\
\text { Decreasing }\end{array}$ & 2 & Campos-S.Maria & $598,99^{\mathrm{b}}$ & $324,51^{\mathrm{a}}$ & 462,00 \\
& 9 & Campos-Caxeta & $537,83^{\mathrm{b}}$ & $318,25^{\mathrm{a}}$ & 428,10 \\
& 6 & B.J.Itabapoana & $355,45^{\mathrm{b}}$ & $326,55^{\mathrm{a}}$ & 341,10 \\
& 10 & Itaperuna & $433,87^{\mathrm{b}}$ & $233,50^{\mathrm{a}}$ & 333,86 \\
& 12 & Campos-Itereré & $422,89^{\mathrm{b}}$ & $125,41^{\mathrm{a}}$ & 274,15 \\
& 4 & S.J.Barra & $425,90^{\mathrm{b}}$ & $114,34^{\mathrm{a}}$ & 270,20 \\
& 7 & Miracema & $381,29^{\mathrm{b}}$ & $145,16^{\mathrm{a}}$ & 263,42 \\
& 1 & S.F.Itabapoana & $232,03^{\mathrm{b}}$ & $125,22^{\mathrm{a}}$ & 178,62 \\
Crescente & 11 & Italva & $179,30^{\mathrm{b}}$ & $95,83^{\mathrm{a}}$ & 137,82 \\
\hline $\begin{array}{l}\text { Increasing } \\
\text { Pequena variação }\end{array}$ & 8 & Campos-Carvão & $419,79^{\mathrm{a}}$ & $652,84^{\mathrm{b}}$ & 536,27 \\
Small variation & 3 & S.A.Pádua & $309,14^{\mathrm{a}}$ & $312,66^{\mathrm{a}}$ & 310,80 \\
\hline
\end{tabular}

Dentro de cada local, médias seguidas de mesma letra não diferem, pelo teste de $\mathrm{F}$, a $5 \%$ de probabilidade.

Within each place, means followed by the same letter do not differ, by $F$ test, at $5 \%$ level of probability. 
TEBALDI et al.

Tabela 5 - Teores médios de Zn (ppm) nos solos, nas épocas seca (Ep1) e chuvosa (Ep2), nas profundidades de 20 (1) e $40 \mathrm{~cm}$ (2), nos diferentes locais, e seus respectivos números de identificação $(\mathrm{N})$

Table 5 - $\quad$ Average $\mathrm{Zn}$ contents (ppm) in the soils, in the dry (Ep1) and rainy (Ep2) seasons, in the depths of 20 (1) and $40 \mathrm{~cm}$ (2) in the different places and the respective identification numbers $(N)$

\begin{tabular}{|c|c|c|c|c|c|}
\hline $\begin{array}{l}\text { Local } \\
\text { Places }\end{array}$ & $\mathrm{N}$ & $\begin{array}{c}\text { Profundidade } \\
\text { Depth }\end{array}$ & Ep1 & Ep2 & $\begin{array}{c}\text { Médias } \\
\text { Means }\end{array}$ \\
\hline \multirow[t]{2}{*}{ Campos-Iterere } & 12 & 1 & $6,33^{\mathrm{a}}$ & $11,33^{\mathrm{b}}$ & 8,83 \\
\hline & & 2 & $3,67^{\mathrm{a}}$ & $13,33^{\mathrm{b}}$ & 8,50 \\
\hline \multirow[t]{2}{*}{ S.A.Pádua } & 8 & 1 & $7,67^{\mathrm{a}}$ & $11,67^{\mathrm{b}}$ & 9,67 \\
\hline & & 2 & $1,67^{\mathrm{a}}$ & $12,33^{\mathrm{b}}$ & 7,00 \\
\hline \multirow[t]{2}{*}{ Campos-S.Maria } & 2 & 1 & $6,33^{\mathrm{a}}$ & $14,33^{b}$ & 10,33 \\
\hline & & 2 & $1,67^{\mathrm{a}}$ & $10,00^{\mathrm{b}}$ & 5,83 \\
\hline \multirow[t]{2}{*}{ Campos-Carvão } & 5 & 1 & $6,00^{\mathrm{a}}$ & $11,67^{\mathrm{b}}$ & 8,83 \\
\hline & & 2 & $4,00 \mathrm{a}$ & $9,33^{b}$ & 6,67 \\
\hline \multirow[t]{2}{*}{ S.F.Itabapoana } & 1 & 1 & $1,67^{\mathrm{a}}$ & $9,00^{\mathrm{b}}$ & 5,33 \\
\hline & & 2 & $0,67^{\mathrm{a}}$ & $10,00^{\mathrm{b}}$ & 5,33 \\
\hline \multirow[t]{2}{*}{ Italva } & 11 & 1 & $1,67^{\mathrm{a}}$ & $8,67^{b}$ & 5,17 \\
\hline & & 2 & $3,33^{\mathrm{a}}$ & $6,33^{b}$ & 4,83 \\
\hline \multirow[t]{2}{*}{ B.J.Itabapoana } & 6 & 1 & $2,00^{\mathrm{a}}$ & $7,33^{\mathrm{b}}$ & 4,67 \\
\hline & & 2 & $1,33^{\mathrm{a}}$ & $7,00^{\mathrm{b}}$ & 4,17 \\
\hline \multirow{2}{*}{ S.M.Madalena } & 3 & 1 & $(0,00)$ & $(0,00)$ & $(0,00)$ \\
\hline & & 2 & $(8,10)$ & $(6,64)$ & $(7,37)$ \\
\hline \multirow[t]{2}{*}{ Itaperuna } & 10 & 1 & $0,00^{\mathrm{a}}$ & $6,67^{b}$ & 3,33 \\
\hline & & 2 & $0,00^{\mathrm{a}}$ & $7,33^{b}$ & 3,67 \\
\hline \multirow[t]{2}{*}{ Campos-Caxeta } & 9 & 1 & $0,00^{\mathrm{a}}$ & $5,33^{b}$ & 2,67 \\
\hline & & 2 & $0,00^{\mathrm{a}}$ & $7,67^{b}$ & 3,83 \\
\hline \multirow[t]{2}{*}{ Miracema } & 7 & 1 & $(0,00)$ & $(0,04)$ & $(0,02)$ \\
\hline & & 2 & $(6,10)$ & $(6,40)$ & $(0,25)$ \\
\hline \multirow[t]{2}{*}{ S.J.Barra } & 4 & 1 & $0,00^{\mathrm{a}}$ & $7,33^{\mathrm{b}}$ & 3,67 \\
\hline & & 2 & $0,00^{\mathrm{a}}$ & $2,00^{\mathrm{a}}$ & 1,00 \\
\hline
\end{tabular}

Dentro de cada local e para cada profundidade, médias seguidas de mesma letra não diferem, pelo teste de $\mathrm{F}$, a $5 \%$ de probabilidade.

Within each place and for each depth, means followed by the same letter do not differ, by F test, at $5 \%$ level of probability. ( ) Média sem variação.

() Means without variation.

baixo encontrado em S.J.Barra.

Os teores de $\mathrm{Zn}$ nas forrageiras (Tabela 6) variaram em função dos locais e das épocas estudados, havendo também interação $(\mathrm{P}<0,01)$ desses fatores. Dez dos doze locais estudados foram mais altos na época seca $(\mathrm{P}<0,05)$, reduzindo-se, em média, a quase um quarto do valor observado na época chuvosa, chegando a valores extremamente baixos e, em certos casos, até não-detectáveis em dois locais. Em S. J. Barra e Campos-Carvão, o comportamento foi de pequena variação, pois não houve diferença $(\mathrm{P}>0,05)$ nos teores médios de $\mathrm{Zn}$ encontrados nas forrageiras nas épocas seca e chuvosa.

Não foi encontrada correlação significativa entre níveis de $\mathrm{Zn}$ nos solos e forrageiras $(\mathrm{r}=0,46, \mathrm{P}=0,06)$.

Conforme GUIMARÃES et al. (1980), o teor de até $15 \mathrm{ppm}$ de $\mathrm{Zn}$ em gramíneas é considerado deficiente, sugerindo necessidade de suplementação deste mineral no período das chuvas nos locais 11,7 , $10,12,1$ e 4 . Este fato também foi observado por
SOUSA et al. (1985), em levantamentos em Roraima, onde a carência maior do mineral foi caracterizada nesse período. Nos demais locais estudados e em algumas épocas, os níveis de $\mathrm{Zn}$ foram caracterizados como adequados; somente na época seca, em Campos-Santa Maria e Italva, atingiram teores que podem ser classificados como alto teor de $\mathrm{Zn}$ nas gramíneas.

Segundo o NRC (1996), a exigência de Zn para gado de corte está em 30 ppm na MS. De acordo com os teores apresentados na Tabela 6, na época seca, somente em São João da Barra o nível nas forrageiras não atende tal exigência, porém, no período das chuvas dos doze locais pesquisados, somente nos locais 5, 2, 6 e 9 os conteúdos das forrageiras são capazes de atender tal exigência e, portanto, os locais $11,8,7,10,12,3,1$, e 4 são considerados deficientes deste mineral nesta época.

É improvável ocorrer toxidez com Zn nos animais, visto que o NRC (1996) determinou o teor de 500 
Tabela 6 - Teores médios de Zn (mg/kg MS) das forrageiras, nas épocas seca (Ep1) e chuvosa (Ep2), nos diferentes locais, e seus respectivos números de identificação (N)

Table 6 - Average Zn contents ( $\mathrm{mg} / \mathrm{kg} D \mathrm{M}$ ) of the forages, in the dry (Ep1) and rainy (Ep2) seasons, in the different places, and the respective identification numbers $(N)$

\begin{tabular}{lclccc}
\hline $\begin{array}{l}\text { Comportamento } \\
\text { Behavior }\end{array}$ & N & $\begin{array}{c}\text { Locais } \\
\text { Places }\end{array}$ & Ep1 & Ep2 & $\begin{array}{c}\text { Médias } \\
\text { Means }\end{array}$ \\
\hline Decrescente & 2 & Campos-S.Maria & $101,70^{\mathrm{b}}$ & $31,80^{\mathrm{a}}$ & 66,70 \\
Decreasing & 6 & B.J.Itabapoana & $65,00^{\mathrm{b}}$ & $40,00^{\mathrm{a}}$ & 54,00 \\
& 9 & Campos-Caxeta & $61,00^{\mathrm{b}}$ & $34,00^{\mathrm{a}}$ & 47,00 \\
& 11 & Italva & $81,30^{\mathrm{b}}$ & $2,20^{\mathrm{a}}$ & 41,70 \\
& 8 & S.A.Pádua & $57,50^{\mathrm{b}}$ & $21,80^{\mathrm{a}}$ & 39,60 \\
& 7 & Miracema & 79,00 & $\mathrm{ND}$ & - \\
& 10 & Itaperuna & $68,60^{\mathrm{b}}$ & $6,80^{\mathrm{a}}$ & 37,70 \\
& 12 & Campos-Itereré & $64,80^{\mathrm{b}}$ & $6,40^{\mathrm{a}}$ & 35,50 \\
& 3 & S.M.Madalena & $48,00^{\mathrm{b}}$ & $23,00^{\mathrm{a}}$ & 35,30 \\
Pequena variação & 4 & S.F.Itabapoana & $57,00^{\mathrm{b}}$ & $0,30^{\mathrm{a}}$ & 28,00 \\
\hline Small variation & 5 & Campos-Carvão & $55,70^{\mathrm{a}}$ & $53,60^{\mathrm{a}}$ & - \\
\hline
\end{tabular}

Dentro de cada local, médias seguidas de mesma letra não diferem, pelo teste de $\mathrm{F}$, a $5 \%$ de probabilidade.

Within each place, means followed by the same letter do not differ, by $F$ test, at $5 \%$ level of probability. $\mathrm{ND}=$ Não-detectado

$N D=$ No detectable

ppm na MS como nível máximo tolerável para os bovinos, o que está bem distante dos teores atingidos pelas gramíneas analisadas neste trabalho.

\section{Cobre}

Os teores de $\mathrm{Cu}$ nos solos (Tabela 7) variaram em função dos locais e das épocas $(\mathrm{P}<0,01)$ estudados, sem diferença entre profundidades. Houve também interação de local e profundidade e de local e época $(\mathrm{P}<0,01)$. Somente em S.J.Itabapoana, não houve diferença entre épocas e nos locais 9 e 10 a análise não foi feita dada a inexistência de variação da média.

Em Bom Jesus do Itabapoana e Campos-Caxeta, a média da época seca foi de 2,28 ppm, enquanto no período das chuvas este valor quase dobrou, atingindo $4,28 \mathrm{ppm}$. Para médias de profundidade, obtiveramse $2,85 \mathrm{ppm}$ na profundidade de $20 \mathrm{~cm}$ e $3,71 \mathrm{ppm}$ na profundidade de $40 \mathrm{~cm}$.

Conforme EINSMINGER et al. (1990), o teor de $\mathrm{Cu}$ disponível nos alimentos é altamente dependente do conteúdo de $\mathrm{Cu}$ nos solos, além de sua absorção e utilização na planta serem afetadas por outros nutrientes como o Mo, $\mathrm{Ca}, \mathrm{Cd}, \mathrm{Zn}$ e $\mathrm{Fe}$.

O coeficiente de correlação entre os níveis de $\mathrm{Cu}$ nos solos e nas forrageiras foi baixo $(r=0,48, P=0,06)$.

Os teores de $\mathrm{Cu}$ das forrageiras foram influenci$\operatorname{ados}(\mathrm{P}<0,01)$ pelo local, pela época e houve interação desses fatores. Em dois locais estudados, os teores de $\mathrm{Cu}$ nas forrageiras (Tabela 8) foram maiores $(\mathrm{P}<0,05)$ na época seca e, em outros seis locais, apresentaram o comportamento inverso, isto é, os teores de $\mathrm{Cu}$
Tabela 7 - Teores médios de $\mathrm{Cu}$ (ppm) nos solos, nas épocas seca (Ep1) e chuvosa (Ep2) nos diferentes locais, e seus respectivos números de identificação $(\mathrm{N})$

Table 7 - Average Cu contents (ppm) in the soils, in the dry (Ep1) and rainy (Ep2) seasons, in the depths of $20 \mathrm{~cm}$ (1) and $40 \mathrm{~cm} \mathrm{(2)} \mathrm{in} \mathrm{the} \mathrm{different} \mathrm{places,} \mathrm{and} \mathrm{the} \mathrm{respective}$ identification numbers $(N)$

\begin{tabular}{lcccc}
\hline $\begin{array}{l}\text { Locais } \\
\text { Places }\end{array}$ & $\mathrm{N}$ & Ep1 & Ep2 & $\begin{array}{c}\text { Médias } \\
\text { Means }\end{array}$ \\
\hline B.J.Itabapoana & 6 & $4,00^{\mathrm{a}}$ & $4,67^{\mathrm{a}}$ & 4,33 \\
Campos-Caxeta & 9 & $(0,00)$ & $(6,61)$ & $(3,30)$ \\
S.A.Pádua & 8 & $5,00^{\mathrm{a}}$ & $11,17^{\mathrm{b}}$ & 8,08 \\
Campos-Carvão & 5 & $4,83^{\mathrm{a}}$ & $8,67^{\mathrm{b}}$ & 6,75 \\
Campos-Itereré & 12 & $3,50^{\mathrm{a}}$ & $5,83^{\mathrm{b}}$ & 4,67 \\
S.M.Madalena & 3 & $1,00^{\mathrm{a}}$ & $4,67^{\mathrm{b}}$ & 2,83 \\
Miracema & 7 & $1,50^{\mathrm{a}}$ & $3,83^{\mathrm{b}}$ & 2,67 \\
S.J.Barra & 4 & $0,83^{\mathrm{a}}$ & $4,50^{\mathrm{b}}$ & 2,67 \\
Italva & 11 & $0,00^{\mathrm{a}}$ & $4,83^{\mathrm{b}}$ & 2,42 \\
Campos-S.Maria & 2 & $1,17^{\mathrm{a}}$ & $3,33^{\mathrm{b}}$ & 2,25 \\
S.F.Itabapoana & 1 & $1,17^{\mathrm{a}}$ & $3,17^{\mathrm{b}}$ & 2,17 \\
Itaperuna & 10 & $(0,00)$ & $(6,90)$ & $(3,45)$ \\
\hline
\end{tabular}

Dentro de cada local e para cada profundidade, médias seguidas de mesma letra não diferem, pelo teste de $\mathrm{F}$, a $5 \%$ de probabilidade. ( ) Média sem variação.

Within each place and for each depth, means followed by the same letter do not differ, by $F$ test, at $5 \%$ level of probability.

() Means without variation.

aumentaram $(\mathrm{P}<0,05)$ da época seca para a época chuvosa e nos demais locais o comportamento foi de pequena variação, sem diferença entre épocas ( $\mathrm{P}>0,05)$. O valor médio mais elevado de $16,53 \mathrm{ppm}$ foi encontrado em Campos-Carvão e o menor, de 5,23 ppm, em S.J. Barra. 
TEBALDI et al.

Tabela 8 - Teores médios de Cu (mg/kg MS) das forrageiras, nas épocas seca (Ep1) e chuvosa (Ep2), nos diferentes locais, e seus respectivos números de identificação $(\mathrm{N})$

Table 8 - Average Cu contents ( $\mathrm{mg} / \mathrm{kg} D M$ ) of forages, in the dry (Ep1) and rainy (Ep2) seasons, in the different places, and the respective identification numbers $(N)$

\begin{tabular}{lrlrrr}
\hline $\begin{array}{l}\text { Comportamento } \\
\text { Behavior }\end{array}$ & N & $\begin{array}{c}\text { Locais } \\
\text { Places }\end{array}$ & Ep1 & Ep2 & $\begin{array}{r}\text { Médias } \\
\text { Means }\end{array}$ \\
\hline $\begin{array}{l}\text { Decrescente } \\
\text { Decreasing }\end{array}$ & 8 & S.A.Pádua & $8,16^{\mathrm{b}}$ & $5,08^{\mathrm{a}}$ & 6,62 \\
Crescente & 7 & Miracema & $6,95^{\mathrm{b}}$ & $3,92^{\mathrm{a}}$ & 5,44 \\
Increasing & 5 & Campos-Carvão & $13,93^{\mathrm{a}}$ & $19,13^{\mathrm{b}}$ & 16,53 \\
& 6 & B.J.Itabapoana & $4,61^{\mathrm{a}}$ & $16,10^{\mathrm{b}}$ & 10,36 \\
& 9 & Campos-Caxeta & $5,65^{\mathrm{a}}$ & $12,57^{\mathrm{b}}$ & 9,11 \\
& 3 & S.M.Madalena & $5,49^{\mathrm{a}}$ & $8,64^{\mathrm{b}}$ & 7,07 \\
& 10 & Itaperuna & $4,62^{\mathrm{a}}$ & $9,34^{\mathrm{b}}$ & 6,98 \\
Pequena variação & 11 & Italva & $4,95^{\mathrm{a}}$ & $8,11^{\mathrm{b}}$ & 6,53 \\
\hline Small variation & 12 & Campos-Itereré & $12,49^{\mathrm{a}}$ & $10,49^{\mathrm{a}}$ & 11,49 \\
& 2 & Campos-S.Maria & $9,13^{\mathrm{a}}$ & $11,06^{\mathrm{a}}$ & 10,10 \\
& 1 & S.F.Itabapoana & $7,19^{\mathrm{a}}$ & $5,44^{\mathrm{a}}$ & 6,32 \\
& 4 & S.J.Barra & $5,37^{\mathrm{a}}$ & $5,09^{\mathrm{a}}$ & 5,23 \\
\hline
\end{tabular}

Dentro de cada local, médias seguidas de mesma letra não diferem, pelo teste de $F$, a $5 \%$ de probabilidade.

Within each place, means followed by the same letter do not differ, by $F$ test, at $5 \%$ level of probability.

Comparando-se os níveis de $\mathrm{Cu}$ obtidos neste trabalho (Tabela 8) com os níveis sugeridos para as forragens por GUIMARÃES et al. (1980), pode-se afirmar que os níveis deste elemento nos locais e também nas épocas analisadas podem ser considerados adequados e altos em alguns locais na época chuvosa, já que os autores classificaram de baixo até 4 ppm, adequado de 5-15 ppm e alto acima de 16 ppm deste elemento nas plantas.

Segundo o NRC (1996), a exigência de Cu para os bovinos é de 10,0 ppm, constatando-se que, somente nos locais $5,12 \mathrm{e} 2$, as forrageiras atendem tal exigência nas duas épocas do ano, porém nos locais 1, 3, 4, 7, 8 e 11 as exigências não são atendidas em ambas épocas do ano. Já nos locais 6,9 e 10 , as exigências não foram atendidas somente na época da seca, pois no período das chuvas este nível pode ser atendido.

\section{Cobalto}

Os teores de Co nos solos (Tabela 9) foram extremamente baixos, não sendo interpretados estatisticamente, por existir variância nula. Em cinco destes locais, não foi detectada a presença deste mineral, possivelmente porque o extrator utilizado não foi adequado, uma vez que há Co nas forrageiras. Já as médias entre épocas e profundidades de solo foram diferenciadas $(\mathrm{P}<0,05)$, embora somente na época seca e na profundidade de $20 \mathrm{~cm}$ não foi detectada a presença de Co, devido ao problema do extrator.

Segundo GUIMARÃES et al. (1980), os níveis de Co das plantas são influenciados pelos teores correspondentes do solo, no entanto, em cinco dos locais não se observou presença de Co no solo, possivelmente devido ao extrator utilizado neste trabalho. A exigência de Co para gado de corte é de $0,10 \mathrm{ppm}$, segundo o NRC (1996), e todas as forrageiras estudadas neste trabalho atingiram tal nível (Tabela 10); portanto, pode-se concluir que não houve carência de Co nos solos analisados.

Os teores de Co nas forrageiras (Tabela 10) variaram em função dos locais e da época do ano, havendo interação desses fatores $(\mathrm{P}<0,01)$. Em dois locais $(\mathrm{P}<0,05)$, foram maiores na época seca $(\mathrm{P}<0,05)$, mas na maioria dos locais o comportamento foi inverso e somente em S. F. Itabapoana não houve diferença entre épocas $(\mathrm{P}>0,05)$. O teor mais alto $(2,70 \mathrm{ppm})$ foi encontrado em Bom Jesus do Itabapoana e o mais baixo (0,70 ppm), em S. F. Itabapoana.

Segundo PEREIRA et al. (1971), a maioria dos pesquisadores reconhece que o nível mínimo de Co na MS das forrageiras para bovinos seja da ordem de 0,06 a $0,08 \mathrm{ppm}$, o que se constata pelos dados obtidos, em que não ocorreu deficiência de Co em bovinos em todos os locais analisados.

Pode-se afirmar que não existe carência de Co na região estudada, bem como não existe risco de toxidez deste elemento por índice elevado nas pastagens, já que o NRC (1996) determina como concentração máxima tolerável o valor de 10,00 ppm.

PEREIRA et al. (1971) constataram deficiências de Co em solos e forrageiras de algumas regiões de Teófilo Otoni, MG e TOKARNIA et al. (1973) identificaram deficiência de Co no Norte do Espírito 
Tabela 9 - Teores médios de Co (ppm) nos solos, nas épocas seca (Ep1) e chuvosa (Ep2), nas profundidades de 20 (P1) e $40 \mathrm{~cm}$ (P2), nos diferentes locais e seus respectivos números de identificação $(\mathrm{N})$

Table 9 - Average Co contents (ppm) in the soils, in the dry (Ep1) and rainy (Ep2) seasons, in the depths of $20(P 1)$ and $40 \mathrm{~cm}(P 2)$ in the different places and the respective identification numbers $(N)$

\begin{tabular}{lcccccc}
\hline $\begin{array}{l}\text { Locais } \\
\text { Places }\end{array}$ & $\mathrm{N}$ & Ep1 & Ep2 & P1 & P2 & $\begin{array}{c}\text { Médias } \\
\text { Means }\end{array}$ \\
\hline S.F. Itabapoana & 1 & 0,000 & 0,057 & 0,000 & 0,057 & 0,028 \\
S.M.Madalena & 3 & 0,000 & 0,040 & 0,017 & 0,023 & 0,020 \\
Campos-Caxeta & 9 & 0,000 & 0,033 & 0,000 & 0,033 & 0,016 \\
S.J.Barra & 4 & 0,000 & 0,008 & 0,008 & 0,000 & 0,004 \\
Campos-S.Maria & 2 & 0,000 & 0,000 & 0,000 & 0,000 & 0,00 \\
Miracema & 7 & 0,000 & 0,000 & 0,000 & 0,000 & 0,00 \\
B.J.Itabapoana & 6 & 0,000 & 0,000 & 0,000 & 0,000 & 0,00 \\
Itaperuna & 10 & 0,000 & 0,000 & 0,000 & 0,000 & 0,00 \\
S.A. Pádua & 8 & 0,000 & 1,805 & 1,002 & 0,803 & 0,90 \\
Campos-Itereré & 12 & 0,000 & 1,520 & 0,818 & 0,702 & 0,76 \\
Campos-Carvão & 5 & 0,055 & 0,595 & 0,367 & 0,283 & 0,32 \\
Italva & 11 & 0,81 & 0,29 & 0,71 & 0,39 & 0,55 \\
\hline
\end{tabular}

Tabela 10 - Teores médios de Co (mg/kg na MS) das forrageiras, nas épocas seca (Ep1) e chuvosa (Ep2), nos diferentes locais, e seus respectivos números de identificação $(\mathrm{N})$

Table 10 - Average Co contents ( $\mathrm{mg} / \mathrm{kg}$ of dry matter) of the forages, in the dry (Ep1) and rainy (Ep2) seasons, in the different places, and the respective identification numbers $(N)$

\begin{tabular}{lclccc}
\hline $\begin{array}{l}\text { Comportamento } \\
\text { Behavior }\end{array}$ & $\mathrm{N}$ & $\begin{array}{l}\text { Locais } \\
\text { Places }\end{array}$ & Ep1 & Ep2 & $\begin{array}{c}\text { Médias } \\
\text { Means }\end{array}$ \\
\hline Decrescente & 8 & S.A.Pádua & $1,31^{\mathrm{b}}$ & $1,01^{\mathrm{a}}$ & 1,20 \\
Decreasing & 7 & Miracema & $1,42^{\mathrm{b}}$ & $0,11^{\mathrm{a}}$ & 0,77 \\
\hline Crescente & 6 & B.J.Itabapoana & $1,10^{\mathrm{a}}$ & $3,51^{\mathrm{b}}$ & 2,70 \\
Increasing & 2 & Campos-S.Maria & $0,89^{\mathrm{a}}$ & $3,68^{\mathrm{b}}$ & 2,33 \\
& 5 & Campos-Carvão & $1,85^{\mathrm{a}}$ & $2,61^{\mathrm{b}}$ & 2,22 \\
& 11 & Italva & $0,81^{\mathrm{a}}$ & $2,66^{\mathrm{b}}$ & 2,21 \\
& 10 & Itaperuna & $1,00^{\mathrm{a}}$ & $2,98^{\mathrm{b}}$ & 1,99 \\
& 12 & Campos-Itereré & $1,27^{\mathrm{a}}$ & $1,91^{\mathrm{b}}$ & 1,59 \\
& 3 & S.M.Madalena & $1,35^{\mathrm{a}}$ & $2,25^{\mathrm{b}}$ & 1,80 \\
& 9 & Campos-Caxeta & $0,95^{\mathrm{a}}$ & $1,85^{\mathrm{b}}$ & 1,39 \\
\hline Pequena variação & 1 & S.F.Itabapoana & $0,76^{\mathrm{a}}$ & $1,23^{\mathrm{b}}$ & 0,99 \\
\hline Small variation & & & $0,88^{\mathrm{a}}$ & 0,70 \\
\hline
\end{tabular}

Dentro de cada local, médias seguidas de mesma letra não diferem, pelo teste $F$, a $5 \%$ de probabilidade. Within each place, means followed by the same letter do not differ, by $F$ test, at $5 \%$ level of probability.

Santo, Vale do Rio São Francisco, Sudeste do Piaú, Maranhão, Pará e áreas do Centro-sul do Mato Grosso. TOKARNIA e BÖBEREINER (1988) também confirmaram ser a deficiência de $\mathrm{Cu}$ e $\mathrm{Co}$ as mais comuns no Brasil, depois do P.

\section{Molibdênio}

Os teores de Mo nos solos (Tabela 11) foram extremamente baixos e não foram interpretados estatisticamente, porém o teor médio na época das chuvas, em alguns locais, foi mais de 100 vezes superior ao da época seca.
Comparando-se os teores de Mo das forrageiras estudadas em cada região com os índices sugeridos por GUIMARÃES et al. (1980), conclui-se que os teores de Mo nos solos analisados são satisfatórios, visto não haver forragem em nenhum dos locais com nível baixo e nem tóxico deste mineral, embora haja variação entre os teores encontrados nos solos, sendo S.J.Barra, com 0,02 ppm, o mais baixo, e CamposCarvão, com 0,68 ppm, o mais alto teor encontrado.

Os teores de Mo das forrageiras foram influenciados pelo local $(\mathrm{P}<0,01)$ e pela época $(\mathrm{P}<0,05)$, 
ocorrendo também interação $(\mathrm{P}<0,01)$ de local e época (Tabela 12). Apenas em Campos-Caxeta, o teor obtido na época seca foi menor que o observado na época chuvosa $(\mathrm{P}<0,05)$, nos demais locais a diferença não foi significativa. Não foi encontrado coeficiente de correlação significativo entre níveis de Mo nos solos e nas forrageiras ( $r=-0,05, P=0,43)$.

Comparando os teores médios de Mo nas forrageiras analisadas (Tabela 12) com os níveis sugeridos por GUIMARÃES et al. (1980), pode-se afirmar que os níveis neste trabalho são adequados e altos, já que propõem até $0,5 \mathrm{ppm}$ como deficiente, 0,6-1,5 ppm como adequado e acima de 1,6 ppm como nível alto de Mo nas forrageiras. Somente em Miracema, na época chuvosa, ocorreu média em desconformidade com os níveis sugeridos pelos autores e também extremamente baixa em relação aos demais teores encontrados neste trabalho.

Segundo ANDRIGUETTO et al. (1988), a exigência de Mo por ruminantes é inferior a $1,0 \mathrm{mg} / \mathrm{kg}$ de MS, excetuando o nível obtido na época chuvosa em Miracema, com teor realmente baixo $(0,17 \mathrm{ppm})$. Na época seca, em Italva, obteve-se nível de 0,88 ppm e em São João da Barra, 0,73 ppm, os demais valores atenderam à exigência recomendada.

Com relação à toxidez deste elemento, o NRC (1996) indica ser de 5,00 mg/kg, à semelhança do citado por CHURCH (1988), portanto, conclui-se não haver tal problema, uma vez que os teores encontrados neste trabalho estão bem abaixo.

\section{Chumbo}

Os teores de $\mathrm{Pb}$ nos solos (Tabela 13) em CamposCarvão e Campos-Iteré, locais 5 e 12, tiveram suas médias locais, entre épocas, e de profundidades acima de 2 ppm. Os dados não foram interpretados estatisticamente, devido à grande ocorrência de valores nulos.

No município de Campos-S.Maria, as médias entre épocas variaram de $0,86 \mathrm{ppm}$ na época seca a $1,01 \mathrm{ppm}$ na época chuvosa. As médias de profundidade neste município foram de $0,23 \mathrm{ppm}$, na profundidade de $20 \mathrm{~cm}$, e quase oito vezes maior, a $40 \mathrm{~cm}$ de profundidade.

Os teores de $\mathrm{Pb}$ das forrageiras foram influenciados pelo local e pela época do ano, com interação desses fatores ( $\mathrm{P}<0,01$, Tabela 14). Em S. A. Pádua e Miracema, os teores de $\mathrm{Pb}$ nas forrageiras foram maiores $(\mathrm{P}<0,05)$ na época seca e em S. J. Barra o comportamento foi de pequena variação $(\mathrm{P}>0,05)$. Nos demais locais, observou-se aumento $(\mathrm{P}<0,05)$ no nível da $\mathrm{Pb}$ das forrageiras da época seca para a chuvosa.
Não foi encontrado coeficiente de correlação significativo entre os níveis de $\mathrm{Pb}$ nos solos e nas forrageiras $(r=0,09, P=0,39)$.

Em Bom Jesus do Itabapoana, Campos-Santa Maria e Italva, na época chuvosa, os teores ultrapassaram o limite de $30 \mathrm{mg} / \mathrm{kg}$, que é considerado o máximo tolerável para bovinos, segundo o NRC (1996). Água

Os teores de Mn (Tabela 15) em águas dos locais 12,4 e 9 , na época seca, e da maioria dos locais, na época chuvosa, variaram de 0,20 a $0,49 \mathrm{ppm}$, em muitos casos superiores à média de 0,295 ppm referida por MAYNARD et al. (1979), mas muito abaixo do nível máximo $(3,23 \mathrm{ppm})$ referido por esses autores. Também CAVALHEIRO et al. (1987) encontraram teores inferiores a $0,1 \mathrm{ppm}$ em águas do Rio Grande do Sul.

Os teores de Fe (Tabela 15) foram superiores à média $(0,439 \mathrm{ppm})$ relatada por MAYNARD et al. (1979), chegando a 3,5 ppm em S.J.Barra na época chuvosa, próximo ao limite máximo de 4,6 ppm relatado por MAYNARD et al. (1979). CAVALHEIRO et al. (1987) e VILELA et al. (1987) encontraram valores de 1,24 e 0,573 ppm de Fe em águas do Rio Grande do Sul e Minas Gerais, respectivamente.

$\mathrm{O}$ teor de $\mathrm{Zn}$ não foi detectado na água de muitos locais, mas o valor encontrado em S.J.Barra na época chuvosa (Tabela 15), de 0,06 ppm, está muito abaixo do valor médio $0,518 \mathrm{ppm}$ relatado por MAYNARD et al. (1979). VILELA et al. (1987) detectaram níveis de 0,01 ppm, em Minas Gerais, e CAVALHEIRO et al. (1987) encontraram valores menores que 0,01 ppm, no Rio Grande do Sul.

$\mathrm{O}$ teor de $\mathrm{Cu}$ não foi detectado na água dos locais 1,8 e 11 na época seca e nos locais 7 e 9 na época chuvosa; nos demais locais, os valores variaram de 0,01 a 0,02 ppm, ou seja, em torno da média $(0,0138$ ppm), mas muito abaixo do valor máximo (0,28 ppm) relatado por MAYNARD et al. (1979). VILELA et al. (1987) encontraram 0,05 ppm em águas de Minas Gerais, enquanto CAVALHEIRO et al. (1987) não encontraram Cu em águas do Rio Grande do Sul. Em Campos-Itereré, na época chuvosa, foi detectado 0,02 ppm do Co na água (Tabela 16); os níveis médio e máximo relatados por MAYNARD et al. (1979) foram de 0,001 e 0,005 , respectivamente.

Os níveis de $\mathrm{Pb}$ (Tabela 16) detectados na água de alguns locais estão na faixa de 0,01 a 0,04 ppm, muito abaixo do limite máximo de segurança $(0,1$ ppm), citado por MAYNARD et al. (1979). 
Tabela 11 - Teores médios de Mo (ppm) nos solos, nas épocas seca (Ep1) e chuvosa (Ep2), nas profundidades de 20 (P1) e $40 \mathrm{~cm}$ (P2), nos diferentes locais, e seus respectivos números de identificação $(\mathrm{N})$

Table 11 - Average Mo contents (ppm) of the soils, in the dry (Ep1) and rainy (Ep2) seasons, in the depths of $20(P 1)$ and $40 \mathrm{~cm}(P 2)$ in the different places, and the respective identification numbers $(\mathrm{N})$

\begin{tabular}{lcccccc}
\hline $\begin{array}{l}\text { Locais } \\
\text { Places }\end{array}$ & $\mathrm{N}$ & $\mathrm{Ep} 1$ & Ep2 & $\mathrm{P} 1$ & $\mathrm{P} 2$ & $\begin{array}{c}\text { Médias } \\
\text { Means }\end{array}$ \\
\hline Itaperuna & 10 & 0,07 & 0,46 & 0,23 & 0,30 & 0,27 \\
B.J.Itabapoana & 6 & 0,06 & 0,42 & 0,26 & 0,21 & 0,24 \\
Campos-Carvão & 5 & 0,15 & 1,20 & 0,69 & 0,66 & 0,68 \\
Campos-Itereré & 12 & 0,16 & 1,05 & 0,63 & 0,58 & 0,61 \\
Miracema & 7 & 0,08 & 0,90 & 0,48 & 0,49 & 0,49 \\
S.A.Pádua & 8 & 0,04 & 0,52 & 0,27 & 0,28 & 0,28 \\
S.M.Madalena & 3 & 0,04 & 0,36 & 0,19 & 0,20 & 0,20 \\
Campos-S.Maria & 2 & 0,05 & 0,48 & 0,27 & 0,26 & 0,26 \\
Campos-Caxeta & 9 & 0,02 & 0,24 & 0,12 & 0,13 & 0,12 \\
S.F.Itabapoana & 1 & 0,00 & 0,10 & 0,05 & 0,05 & 0,05 \\
S.J.Barra & 4 & 0,00 & 0,04 & 0,01 & 0,04 & 0,02 \\
Italva & 11 & 0,06 & 0,60 & 0,39 & 0,26 & 0,33 \\
\hline
\end{tabular}

Tabela 12 - Teores médios de Mo (mg/kg MS) das forrageiras, nas épocas seca (Ep1) e chuvosa (Ep2), nos diferentes locais, e seus respectivos números de identificação (N)

Table 12 - Average Mo contents ( $\mathrm{mg} / \mathrm{kg} \mathrm{DM}$ ) of the forages, in the dry (Ep1) and rainy (Ep2) seasons, in the different places, and the respective identification numbers $(N)$

\begin{tabular}{lclccc}
\hline $\begin{array}{l}\text { Comportamento } \\
\text { Behavior }\end{array}$ & $\mathrm{N}$ & $\begin{array}{l}\text { Locais } \\
\text { Places }\end{array}$ & Ep1 & Ep2 & $\begin{array}{c}\text { Médias } \\
\text { Means }\end{array}$ \\
\hline $\begin{array}{l}\text { Crescente } \\
\text { Increasing }\end{array}$ & 9 & Campos-Caxeta & $1,19^{\mathrm{a}}$ & $1,95^{\mathrm{b}}$ & 1,58 \\
\hline Pequena variação & 10 & Itaperuna & $3,17^{\mathrm{a}}$ & $4,58^{\mathrm{a}}$ & 3,88 \\
Small variation & 2 & Campos-S.Maria & $1,19^{\mathrm{a}}$ & $4,21^{\mathrm{a}}$ & 2,70 \\
& 3 & S.M.Madalena & $2,14^{\mathrm{a}}$ & $1,81^{\mathrm{a}}$ & 2,05 \\
& 6 & B.J. Itabapoana & $1,10^{\mathrm{a}}$ & $3,50^{\mathrm{a}}$ & 2,30 \\
& 11 & Italva & $0,88^{\mathrm{a}}$ & $2,96^{\mathrm{a}}$ & 1,92 \\
& 5 & Campos-Carvão & $1,24^{\mathrm{a}}$ & $1,95^{\mathrm{a}}$ & 1,60 \\
& 4 & S.J.Barra & $0,73^{\mathrm{a}}$ & $1,09^{\mathrm{a}}$ & 0,91 \\
& 12 & Campos-Itereré & $1,24^{\mathrm{a}}$ & $1,28^{\mathrm{a}}$ & 1,26 \\
& 1 & S.F.Itabapoana & $1,00^{\mathrm{a}}$ & $1,19^{\mathrm{a}}$ & 1,10 \\
& 8 & S.A.Pádua & $1,30^{\mathrm{a}}$ & $0,77^{\mathrm{a}}$ & 1,07 \\
& 7 & Miracema & $1,43^{\mathrm{a}}$ & $0,17^{\mathrm{a}}$ & 0,80 \\
\hline
\end{tabular}

Dentro de cada local, médias seguidas de mesma letra não diferem, pelo teste $F$, a $5 \%$ de probabilidade. Within each place, means followed by the same letter do not differ, by $F$ test, at $5 \%$ level of probability. 
Tabela 13 - Teores médios de Pb (ppm) nos solos, nas épocas seca (Ep1) e chuvosa (Ep2), nas profundidades de 20 (P1) e $40 \mathrm{~cm}$ (P2), nos diferentes locais, e seus respectivos números de identificação $(\mathrm{N})$.

Table 13 - Average Pb contents (ppm) of soils, in the dry (Ep1) and rainy (Ep2) seasons, in the depths of 20 $(P 1)$ and $40 \mathrm{~cm}(P 2)$, in the different places and the respective identification numbers $(N)$

\begin{tabular}{lcccccc}
\hline $\begin{array}{l}\text { Locais } \\
\text { Places }\end{array}$ & $\mathrm{N}$ & $\mathrm{Ep}^{1}$ & $\mathrm{Ep}^{2}$ & $\mathrm{P}^{1}$ & $\mathrm{P}^{2}$ & $\begin{array}{c}\text { Médias } \\
\text { Means }\end{array}$ \\
\hline Campos-Carvão & 5 & 2,79 & 2,42 & 2,35 & 2,85 & 2,60 \\
Miracema & 7 & 0,43 & 0,56 & 0,50 & 0,49 & 0,49 \\
Campos-Itereré & 12 & 2,02 & 2,43 & 2,17 & 2,28 & 2,22 \\
S.M.Madalena & 3 & 0,14 & 0,55 & 0,28 & 0,41 & 0,35 \\
Campos-Caxeta & 9 & 0,00 & 0,40 & 0,00 & 0,39 & 0,20 \\
S.F.Itabapoana & 1 & 0,00 & 0,35 & 0,00 & 0,35 & 0,17 \\
S.J. Barra & 4 & 0,00 & 0,07 & 0,07 & 0,00 & 0,03 \\
B.J.Itabapoana & 6 & 0,00 & 0,04 & 0,04 & 0,00 & 0,02 \\
Itaperuna & 10 & 0,00 & 0,02 & 0,01 & 0,00 & 0,005 \\
S.A.Pádua & 8 & 0,00 & 0,00 & 0,00 & 0,00 & 0,00 \\
Italva & 11 & 0,00 & 0,00 & 0,00 & 0,00 & 0,00 \\
Campos-S.Maria & 2 & 0,86 & 1,01 & 0,23 & 1,65 & 0,94 \\
\hline
\end{tabular}

Tabela 14 - Teores médios de Pb (mg/kg MS) das forrageiras nas épocas seca (Ep1) e chuvosa (Ep2) nos diferentes locais e seus respectivos números de identificação (N)

Table14 - Average Pb contents ( $\mathrm{mg} / \mathrm{kg} D M$ ) of forages, in the dry (Ep1) and rainy (Ep2) seasons, in the different places and the respective identification numbers $(N)$

\begin{tabular}{lclrcr}
\hline $\begin{array}{l}\text { Comportamento } \\
\text { Behavior }\end{array}$ & $\mathrm{N}$ & \multicolumn{1}{c}{$\begin{array}{c}\text { Locais } \\
\text { Places }\end{array}$} & $\mathrm{Ep}^{1}$ & $\mathrm{Ep}^{2}$ & $\begin{array}{c}\text { Médias } \\
\text { Means }\end{array}$ \\
\hline $\begin{array}{l}\text { Decrescente } \\
\text { Decreasing }\end{array}$ & 8 & S.A.Pádua & $10,10^{\mathrm{b}}$ & $4,20^{\mathrm{a}}$ & 7,15 \\
\hline Crescente & 7 & Miracema & $12,10^{\mathrm{b}}$ & $0,00^{\mathrm{a}}$ & 6,05 \\
Increasing & 6 & B.J. Itabapoana & $9,26^{\mathrm{a}}$ & $38,36^{\mathrm{b}}$ & 23,81 \\
& 2 & Campos-S.Maria & $8,18^{\mathrm{a}}$ & $32,15^{\mathrm{b}}$ & 20,16 \\
& 11 & Italva & $5,36^{\mathrm{a}}$ & $31,85^{\mathrm{b}}$ & 18,61 \\
& 3 & S.M.Madalena & $11,00^{\mathrm{a}}$ & $22,40^{\mathrm{b}}$ & 16,70 \\
& 10 & Itaperuna & $5,40^{\mathrm{a}}$ & $27,60^{\mathrm{b}}$ & 16,50 \\
& 5 & Campos-Carvão & $9,00^{\mathrm{a}}$ & $21,10^{\mathrm{b}}$ & 15,00 \\
& 9 & Campos Caxeta & $8,60^{\mathrm{a}}$ & $17,20^{\mathrm{b}}$ & 12,90 \\
& 12 & Campos-Itereré & $7,60^{\mathrm{a}}$ & $17,85^{\mathrm{b}}$ & 12,70 \\
& 1 & S.F.Itabapoana & $2,94^{\mathrm{a}}$ & $6,28^{\mathrm{b}}$ & 4,60 \\
\hline Pequena variação & 4 & S.J.Barra & $5,90^{\mathrm{a}}$ & $5,54^{\mathrm{a}}$ & 5,72
\end{tabular}

Small variation

Dentro de cada local, médias seguidas de mesma letra não diferem, pelo teste $\mathrm{F}$, a $5 \%$ de probabilidade. Within each place, means followed by the same letter do not differ, by $F$ test, at $5 \%$ level of probability. 
Rev. bras. zootec.

Tabela 15 - Teores de Mn, Fe, Zn e Cu da água, em mg/L, nas épocas seca e chuvosa nos diferentes locais e seus respectivos números de identificação $(\mathrm{N})$

Table 15 - Mn, $\mathrm{Fe}, \mathrm{Zn}$ and Cu contents of water, in $\mathrm{mg} / \mathrm{L}$, in the dry and rainy seasons, in the different places and the respective identification numbers $(N)$

\begin{tabular}{|c|c|c|c|c|c|c|c|c|c|}
\hline \multirow{2}{*}{$\begin{array}{l}\text { Local } \\
\text { Place }\end{array}$} & $\mathrm{N}$ & $\mathrm{Mn}$ & $\mathrm{Fe}$ & $\mathrm{Zn}$ & $\mathrm{Cu}$ & $\mathrm{Mn}$ & $\mathrm{Fe}$ & $\mathrm{Zn}$ & $\mathrm{Cu}$ \\
\hline & \multicolumn{5}{|c|}{$\begin{array}{l}\text { Época seca } \\
\text { Dry season }\end{array}$} & \multicolumn{4}{|c|}{$\begin{array}{c}\text { Época chuvosa } \\
\text { Rainy season }\end{array}$} \\
\hline S .F.Itabapoana & 1 & $\mathrm{ND}$ & ND & $\mathrm{ND}$ & $\mathrm{ND}$ & 0,05 & 0,01 & $\mathrm{ND}$ & 0,01 \\
\hline Campos-S.Maria & 2 & 0,01 & 0,01 & $\mathrm{ND}$ & 0,01 & 0,04 & 0,01 & ND & 0,01 \\
\hline S.M. Madalena & 3 & $\mathrm{ND}$ & 1,09 & ND & 0,01 & 0,09 & 1,67 & ND & 0,01 \\
\hline S.J.Barra & 4 & 0,02 & 0,40 & $\mathrm{ND}$ & 0,02 & 0,12 & 3,50 & 0,06 & 0,02 \\
\hline Campos-Carvão & 5 & 0,10 & 0,03 & ND & 0,01 & 0,02 & 0,02 & ND & 0,01 \\
\hline B.J.Itabapoana & 6 & $\mathrm{ND}$ & 0,01 & $\mathrm{ND}$ & 0,01 & 0,01 & 0,08 & ND & 0,01 \\
\hline Miracema & 7 & $\mathrm{ND}$ & 1,19 & $\mathrm{ND}$ & 0,01 & 0,04 & 0,27 & ND & ND \\
\hline S.A.Pádua & 8 & $\mathrm{ND}$ & 0,69 & $\mathrm{ND}$ & ND & 0,02 & 0,18 & ND & 0,01 \\
\hline Campos-Caxeta & 9 & 0,02 & 3,35 & $\mathrm{ND}$ & 0,01 & 0,49 & 0,01 & ND & ND \\
\hline Itaperuna & 10 & 0,01 & 0,01 & $\mathrm{ND}$ & 0,01 & 0,01 & 0,01 & $\mathrm{ND}$ & 0,01 \\
\hline Italva & 11 & $\mathrm{ND}$ & 0,51 & $\mathrm{ND}$ & $\mathrm{ND}$ & $\mathrm{ND}$ & 0,85 & $\mathrm{ND}$ & 0,01 \\
\hline Campos-Itereré & 12 & 0,03 & 0,01 & 0,01 & 0,01 & $\mathrm{ND}$ & 0,87 & $\mathrm{ND}$ & 0,01 \\
\hline
\end{tabular}

ND = Não-detectado.

$N D=$ No detectable.

Tabela 16 - Teores de Co, Mo e Pb (mg/L) das águas, nas épocas seca e chuvosa, nos diferentes locais, e seus respectivos números de identificação $(\mathrm{N})$

Table 16 - Co, Mo and $\mathrm{Pb}$ contents $(\mathrm{mg} / \mathrm{L})$ of the water in the dry and rainy seasons, in the different places, and the respective identification numbers $(N)$

\begin{tabular}{|c|c|c|c|c|c|c|c|}
\hline \multirow{2}{*}{$\begin{array}{l}\text { Local } \\
\text { Place }\end{array}$} & \multirow[t]{2}{*}{$\mathrm{N}$} & Co & Mo & $\mathrm{Pb}$ & \multirow[t]{2}{*}{$\mathrm{Co}$} & Mo & $\mathrm{Pb}$ \\
\hline & & \multicolumn{3}{|c|}{$\begin{array}{c}\text { Época seca } \\
\text { Dry season }\end{array}$} & & \multicolumn{2}{|c|}{$\begin{array}{c}\text { Época chuvosa } \\
\text { Rainy season }\end{array}$} \\
\hline S.F.Itabapoana & 1 & $\mathrm{ND}$ & ND & 0,01 & ND & $\mathrm{ND}$ & $\mathrm{ND}$ \\
\hline Campos-S.Maria & 2 & $\mathrm{ND}$ & ND & 0,01 & ND & $\mathrm{ND}$ & $\mathrm{ND}$ \\
\hline S.M. Madalena & 3 & $\mathrm{ND}$ & ND & $\mathrm{ND}$ & ND & $\mathrm{ND}$ & $\mathrm{ND}$ \\
\hline S.J.Barra & 4 & $\mathrm{ND}$ & 0,01 & ND & ND & $\mathrm{ND}$ & 0,01 \\
\hline Campos-Carvão & 5 & ND & 0,02 & ND & ND & 0,01 & 0,02 \\
\hline B.J.Itabapoana & 6 & $\mathrm{ND}$ & 0,01 & 0,01 & ND & $\mathrm{ND}$ & 0,01 \\
\hline Miracema & 7 & $\mathrm{ND}$ & ND & ND & ND & $\mathrm{ND}$ & 0,02 \\
\hline S.A.Pádua & 8 & $\mathrm{ND}$ & ND & ND & ND & $\mathrm{ND}$ & 0,02 \\
\hline Campos-Caxeta & 9 & $\mathrm{ND}$ & ND & 0,01 & ND & $\mathrm{ND}$ & $\mathrm{ND}$ \\
\hline Itaperuna & 10 & ND & 0,02 & 0,03 & ND & 0,01 & 0,04 \\
\hline Italva & 11 & $\mathrm{ND}$ & 0,01 & 0,01 & ND & $\mathrm{ND}$ & $\mathrm{ND}$ \\
\hline Campos-Itereré & 12 & 0,02 & ND & 0,01 & ND & $\mathrm{ND}$ & $\mathrm{ND}$ \\
\hline
\end{tabular}

$\mathrm{ND}=$ Não-detectado.

$N D=$ No detectable.

A partir dos resultados dos teores minerais encontrados nas amostras de água analisadas, neste trabalho, confrontados com os índices divulgados por vários pesquisadores brasileiros e americanos, de modo geral, pode-se afirmar que a composição mineral das águas de superfície da região estudada se encontra dentro de níveis satisfatórios. Pode-se também constatar que nenhum dos valores encontrados está próximo do limite de toxidez para os animais.

\section{Conclusões}

Observaram-se deficiências de zinco nos solos, tanto na época seca, como na época chuvosa.

Nas forrageiras, ocorreram baixos níveis de zinco e cobre, nas duas épocas estudadas, os quais não são capazes de atender as exigências mínimas de crescimento e engorda dos bovinos.

As concentrações de minerais nas forrageiras estu- 
dadas variaram com o tipo de solo e a época do ano.

Nas forrageiras, o nível de Mo na época das chuvas, em cinco locais analisados, ultrapassou o nível de 1,6 ppm considerado alto; em dois locais, em ambas épocas, os teores deste mineral ultrapassaram esse nível.

Em três locais, os teores de chumbo das forrageiras ultrapassaram o limite de $30 \mathrm{mg} / \mathrm{kg}$, que é considerado o máximo tolerado para bovinos.

Os teores de Co das forrageiras foram normais e até elevados em alguns locais.

De modo geral, pode-se afirmar que nenhum elemento mineral comprometeu a qualidade das águas estudadas, para sua utilização com os animais domésticos.

\section{Agradecimento}

Ao Prof. Dr. Doracy Pessoa Ramos do Laboratório de Solos, do Centro de Ciências e Tecnologias Agropecuárias da UENF, pela liberação das fotos da região, e ao Dr. Celso Vainer Manzatto, pela identificação e classificação dos Solos.

À ARACRUZ CELULOSE S.A., na pessoa do Dr. Sebastião da Fonseca, pelas facilidades oferecidas nas análises das amostras.

\section{Referências Bibliográficas}

ANDRIGUETTO, J.M., PERLY, L., MINARDI, I., GEMAEL, A. et al.1988. Nutrição animal, 4. ed., v.1, Nobel, São Paulo. p.143-246.

CARDOSO, R.M. 1983. Minerais para ruminantes. Viçosa: UFV, n.158. 86p.

CAVALHEIRO, A.C.L., TRINDADE, D.S., WEDERKEHR, N.A. et al. Concentração de alguns minerais em águas do Rio Grande do Sul. In: REUNIÃO ANUAL DA SOCIEDADE BRASILEIRA DE ZOOTECNIA, 24, Brasília, 1987. Anais.... Brasília: SBZ, 1987, p.147.

CHURCH, C.D. 1988. El Ruminante: fisiologia digestivaynutrición. Editorial Acribia - S.A., Zaragoza (España). p.386-387.

CONRAD, J.H., McDOWELL, L.R., ELLIS, G.L. et al. 1985. Minerais para ruminantes em pastejo em regiões tropicais. Traduzido por EUCLIDES, V.P.B. EMBRAPA-CNPGC, Campo Grande. 91p.

ENSMINGER, M.E., OLDFIELD, J.E., HEINEMANN, W.W. 1990. Feeds and nutrition (Formely, Feeds and Nutritiom complete) 2. ed. The Ensminger Publishing Company. 1544p.

GRAHAN, T.W. 1991. Trace element deficiencies in cattle In: Beef cattle nutrition. The Veterinary Clinics of North America - Food Animal Practice, 7(1):277-306.

GUIMARÃES, P.T.G., FERREIRA, J.G., CARVALHO, J.G. et al. 1980. Adubação de pastagens. Inf. Agropec., 6(70):34-52.

MARQUES, D.C., MARQUES JR., A.P., FERREIRA, P.M. et al. 1981. Criação de bovinos. 4.ed. Belo Horizonte. 479p.

MARTIN, L.C.T. 1993. Nutrição mineral de bovinos de corte. São Paulo: Editora Nobel. 173p.

MAYNARD, L.A., LOSLI, J.K., HINTZ, H.F. et al. 1978.
Animal nutrition. 7. ed. Mc Graw-Hill Books Company, NY. $620 \mathrm{p}$.

McDOWELL, L.R., FICK, K.R., AMMERMAN, C.B. et al. Novos minerais essenciais e toxidez em nutrição animal. In: SIMPÓSIO LATINO-AMERICANO SOBRE PESQUISA EM NUTRIÇÃO DE RUMINANTES EM PASTAGENS, Belo Horizonte, 1976. Anais...Belo Horizonte, 1976, 367p.

MILLER, J.K., RAMSEY, N. 1988. Elementos vestigiales. In: CHURCH, C.D. El ruminante: fisiologia digestiva y nutrición, Editorial Acribia S.A. p.391-456.

MILLER, W.J. Mineral and vitamin nutrition of dairy cattle. $J$. Dairy Sci., 64(06):1196-1206.

NATIONAL RESEARCH COUNCIL - NRC. 1996. Nutrient requirements of beefcatlle. 7. ed. Washigton National Academy of Science. 242p.

PEREIRA, J.A.A., SILVA, D.J., BRAGA, J.M. et al. 1971. Teores de fósforo, cobre e cobalto em algumas pastagens do Município de Teófilo Otoni, Minas Gerais. Experientiae, 12 (6):155-188.

SHIRLEY, R.L., CARVALHO, J.H. A água como fonte de minerais. In: SIMPÓSIO LATINO AMERICANO SOBRE PESQUISAS EM NUTRIÇÃO MINERAL DE RUMINANTES EM PASTAGENS, Belo Horizonte, 1976. Anais.... Belo Horizonte, 1976, p.34-50.

SILVA, R.M. 1981. Minerais na nutrição de ruminantes. Inf. Agropec., 7(78):58-61.

SOUSA, J.C., DARSIE, G. 1985. Deficiências minerais em bovinos de Roraima, Brasil. I - Zinco e Cobalto. Pesq. Agropec. Bras., 20(11):1309-16.

SOUSA, J.C., GOMES, R.F.C., SILVA, J.M. et al. 1985. Suplementação mineral em novilhos de corte em pastagens adubadas com capim colonião. Pesq. Agropec. Bras., 20(2): 259-69.

TEBALDI, F.L.H., COELHO DA SILVA, J.F., VASQUEZ, H.M. et al. 2000. Composição mineral das pastagens das regiões Norte e Noroeste do Estado do Rio de Janeiro. 1 - Cálcio, fósforo, magnésio, potássio, sódio e enxofre. Rev. bras. zootec., 29(2):603-615.

TEIXEIRA, J.C. 1991. Nutrição dos ruminantes. Lavras, MG: ESAL/FAEPE. 267p.

TOKARNIA, C.H., DÖBEREINER, J. 1973. Diseases caused by mineral deficiencies in cattle raised under range conditions in Brazil, a review. Pesq. Agropec. Bras., 8 (sup 1.):1-6.

TOKARNIA, C.H., DÖBEREINER, J., MORAES, S.S. 1988. Situação atual e perspectivas da investigação sobre nutrição mineral em bovinos no Brasil. Pesq. Vet. Bras., 8(1/2):1-16.

VILELA, H., SILVA, J.F.C., PAULINELLI, M.T. et al. Conteúdo em minerais das águas de superfície da bacia hidrográfica do Alto São Francisco do Estado de Minas Gerais. In: REUNIÃO ANUAL DA SOCIEDADE BRASILEIRA DE ZOOTECNIA, 24, Brasília, DF, 1987. Anais... . Brasília: SBZ, 1987, p.149.
Recebido em: 30/03/98 Aceito em: 27/09/99 